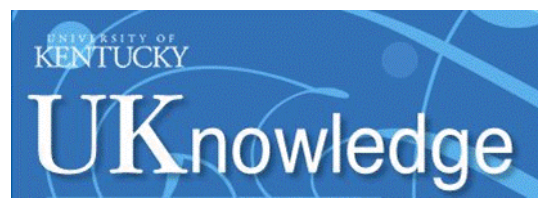

University of Kentucky

UKnowledge

\title{
Beliefs About Savoring in Older Adulthood: Aging and Perceived Health Affect Temporal Components of Perceived Savoring Ability
}

\author{
Paul Jefferson Geiger \\ University of Kentucky, paulgeiger10@gmail.com \\ Jennifer N. Morey \\ Thomas Nelson Community College \\ Suzanne C. Segerstrom \\ University of Kentucky, segerstrom@uky.edu
}

Follow this and additional works at: https://uknowledge.uky.edu/psychology_facpub

Part of the Health Psychology Commons, and the Personality and Social Contexts Commons

Right click to open a feedback form in a new tab to let us know how this document benefits you.

\section{Repository Citation}

Geiger, Paul Jefferson; Morey, Jennifer N.; and Segerstrom, Suzanne C., "Beliefs About Savoring in Older Adulthood: Aging and Perceived Health Affect Temporal Components of Perceived Savoring Ability" (2017). Psychology Faculty Publications. 179.

https://uknowledge.uky.edu/psychology_facpub/179

This Article is brought to you for free and open access by the Psychology at UKnowledge. It has been accepted for inclusion in Psychology Faculty Publications by an authorized administrator of UKnowledge. For more information, please contact UKnowledge@lsv.uky.edu. 


\title{
Beliefs About Savoring in Older Adulthood: Aging and Perceived Health Affect Temporal Components of Perceived Savoring Ability
}

\author{
Digital Object Identifier (DOI) \\ https://doi.org/10.1016/j.paid.2016.09.049 \\ Notes/Citation Information \\ Published in Personality and Individual Differences, v. 105, p. 164-169. \\ (C) 2016 Elsevier Ltd. All rights reserved.
}

This manuscript version is made available under the CC-BY-NC-ND 4.0 license https://creativecommons.org/licenses/by-nc-nd/4.0/.

The document available for download is the author's post-peer-review final draft of the article. 
Published in final edited form as:

Pers Individ Dif. 2017 January 15; 105: 164-169. doi:10.1016/j.paid.2016.09.049.

\title{
Beliefs about savoring in older adulthood: Aging and perceived health affect temporal components of perceived savoring ability
}

\author{
Paul J. Geiger ${ }^{1}$, Jennifer N. Morey ${ }^{2}$, and Suzanne C. Segerstrom ${ }^{1}$ \\ 1 University of Kentucky \\ ${ }^{2}$ Thomas Nelson Community College
}

\begin{abstract}
The ability to savor positive life events is associated with higher emotional well-being; however, few studies have examined savoring ability in older adults. The present study used a longitudinal design to examine changes in perceived savoring abilities and associations with perceived health in older adulthood. Older adults $(N=131)$ reported on beliefs about savoring and perceived health at baseline and $2 \frac{1}{2}$ years later. Perceived anticipation (savoring the future) and reminiscing (savoring the past) abilities declined from baseline to follow-up. Better perceived health at baseline predicted greater perceived reminiscing and anticipation abilities at follow-up. Greater perceived ability to savor the present moment at baseline predicted better perceived health at follow-up. Aging and poorer health focus older adults' thoughts on present-moment pleasures, which may benefit health, but may also lead to reductions in perceived anticipation and reminiscing abilities.
\end{abstract}

\section{Keywords}

SAVORING BELIEFS; AFFECT REGULATION; PERCEIVED HEALTH; AGING

Savoring is the ability to actively regulate positive emotions by attending to and appreciating pleasurable life events (Bryant, 1989). Savoring has three temporal components: reminiscing about past positive events (savoring the past), savoring or enjoying positive events in the present, and anticipating future positive events (savoring the future) (Bryant, 2003). Previous research has examined perceived savoring abilities in order to understand individual differences in managing emotions. Perceived savoring abilities predict savoring engagement (Bryant, 2003) and may help explain why some individuals savor while others do not. Although research on savoring beliefs continues to grow, few studies have investigated savoring beliefs in older adults. The purpose of the present study is to address the predictors

Address correspondence to Paul J. Geiger, Department of Psychology, University of Kentucky, 115 Kastle Hall, Lexington, KY, 40506-0044. paulgeiger10@gmail.com.

Paul J. Geiger and Suzanne C. Segerstrom, Department of Psychology, University of Kentucky. Jennifer M. Morey, Department of Psychology, Thomas Nelson Community College.

The authors have no conflicts of interest to disclose.

Publisher's Disclaimer: This is a PDF file of an unedited manuscript that has been accepted for publication. As a service to our customers we are providing this early version of the manuscript. The manuscript will undergo copyediting, typesetting, and review of the resulting proof before it is published in its final citable form. Please note that during the production process errors may be discovered which could affect the content, and all legal disclaimers that apply to the journal pertain. 
and consequences of changes in perceived savoring abilities in the context of older adulthood.

\section{Physical Health, Aging and Affect Regulation}

As people age or experience ill health, future time may be perceived as becoming limited, and temporal focus shifts to favor the past and present moment over the future (Carstensen et al., 1999; Kooij \& Van De Vorde, 2011; Spreng \& Levine, 2006). Socioemotional selectivity theory (SST; Carstensen et al., 1999) describes how the perception of limited time remaining in life explains older adults' motivations and goals. When time remaining in life is perceived as limited, older adults place more value on emotionally meaningful goals that enhance present-moment experiences (e.g., Carstensen et al., 2003). Despite frequent experiences of negative events such as health decline and loss, as well as approaching the end of life, older adults effectively redirect attention from negative emotions and focus on positive emotions (Carstensen et al., 2003; Mammarella et al., 2016).

In addition to chronological aging, subjective physical health affects how future time is perceived (e.g., Charles \& Carstensen, 2010). For example, symptomatic HIV-positive patients had goals similar to those of older adults, compared with non-symptomatic HIV positive patients (Carstensen et al., 1999). Subjective physical health is positively correlated with future time perspective, such that individuals who perceive themselves to be in better health report more expansive future time perspective (e.g., Bal et al., 2010). Perceived physical health affects time perception in a way that may influence perceptions of affect regulation ability in older adults.

\section{Savoring Beliefs and Well-being}

Perceived savoring abilities may be important for well-being in late life because older adults are motivated to effectively upregulate positive emotions, and savoring is one means to do that (e.g., Charles \& Carstensen, 2010). Young adults who engage in more savoring report higher psychological well-being and lower ill-being (Bryant, 2003; Hurley \& Kwon, 2012). Using the Savoring Beliefs Inventory (SBI; Bryant, 2003), savoring beliefs total scores (summed across the three temporal subscales of anticipation, reminiscing, and savoring the present (henceforth, referred to as "savoring")) related positively to levels of positive affect, optimism, and life satisfaction. SBI total scores were negatively associated with outcomes including neuroticism, hopelessness, and depression. In addition, differences were found on the subscale level. Among young adults, perceived anticipation ability was more strongly related to optimism and negatively related to hopelessness compared with perceived savoring and reminiscing abilities. However, this may not generalize to older adults, as it may be more difficult to engage in anticipation. Older adults have difficulty generating and anticipating future events due to declines in future time perspective and episodic memory (Rendell et al., 2012; Spreng \& Levine, 2006). Rather, older adults may benefit more from reminiscing ability. Reminiscence, recalling memories from the past, effectively boosts wellbeing in late life (Bohlmeijer et al., 2007). 
In general, perceived savoring ability has emerged as the best subscale predictor of wellbeing. In addition to predicting higher levels of happiness, perceived savoring ability predicted intensity and frequency of positive emotions, positive affect, and satisfaction with life in younger adults (Hurley \& Kwon, 2013; Quoidbach et al., 2010). These findings spurred the development of an intervention to increase savoring the present, which reduced self-reported depression and negative affect in younger adults (Hurley \& Kwon, 2012). In addition to improvements in psychological well-being, present moment awareness, a quality of savoring the present, has been linked to gains in physical health (e.g., Grossman et al., 2004). Additionally, positive emotions may improve physical health (e.g., Ong et al., 2011), providing additional support for the hypothesized link between perceived savoring ability and physical health. However, this relationship has not been studied in older adults.

Perceived savoring ability may naturally increase when future time perception is limited. Laboratory tasks creating a limited perception of time remaining in life increased subjective happiness in college students, suggesting that students enhanced enjoyment of the present due to increased temporal awareness (Kurtz, 2008). Based on these findings, it would seem that older adults may savor the present more, provided their perception of time is limited. However, another study using self-report measures linked higher levels of savoring ability to expansive, but not limited, future time perspective (Ramsey \& Gentzler, 2014).

\section{The Present Study}

The present study extends savoring beliefs research to older adulthood by examining the temporal facets of savoring beliefs as they relate to factors affecting time remaining in life (aging and perceived physical health) over $2 \frac{1}{2}$ years in older adults. We chose to examine facets of savoring beliefs, rather than the total score, as aging and perceived health were hypothesized to affect the subscales differentially.

The first set of hypotheses concerned changes in savoring beliefs over time. For this study, we interpreted the $2 \frac{1}{2}$ year change in time as an effect of aging. We hypothesized that over the course of the study, perceived anticipation ability would significantly decrease, but perceived savoring and reminiscing abilities ability would increase. Furthermore, given that better health should extend perceived time remaining in life, we hypothesized that better perceived health would predict greater perceived anticipation ability.

The second set of hypotheses concerned effects of savoring beliefs on health. We hypothesized that higher perceived savoring and reminiscing abilities, but not anticipation, would predict better perceived health at follow-up. Because perceived reminiscing and savoring abilities should improve positive affect among older adults, and positive affect has been related to health in this and other samples (e.g., Pressman \& Bowlin, 2014) we also tested whether positive affect mediated effects of savoring on health. 


\section{Method}

\section{Participants}

Participants were 131 community-dwelling older adults (58\% female, $95 \%$ white) recruited from a research volunteer subject pool. The sample was, on average, 74 years of age at enrollment (range $=60-93$ ), well educated $(M=16$ years, range $=11-22$ years $)$, and married (100\%). Inclusion criteria for the parent study were 60 years or older and married at enrollment. Because the parent study included assessment of the immune system, exclusion criteria included diseases affecting the immune system; chemotherapy/radiation in the past 5 years; the use of opiates or systemic steroids; or the use of more than two of the following medication groups: psychotropics, antihypertensives, hormone replacement, and thyroid supplements. This set of exclusion criteria was meant to ensure a relatively healthy sample. Only one individual per couple was allowed to enroll to avoid dyadic dependency in the data.

\section{Procedures}

All procedures were approved by the Institutional Review Board. Older participants expressing interest in research were contacted and screened. After an explanation of the study and its procedures, written informed consent was obtained. Participants were interviewed at semi-annual visits in their homes. Measures of interest for the current study were collected at Visit 1 (baseline) and Visit 6 (follow-up), spanning 2 1/2 years. Participants received a $\$ 20$ gift card following each visit.

For the current study, 233 person-visits were available for analysis (131 at baseline; 102 at follow-up). Data were missing at follow-up due to dropouts $(N=25)$, deaths $(N=2)$, outliers (more than $3 \mathrm{SD}$ outside the mean on all of the savoring facets; $N=1$ ), and skipped visits $(N=1)$. Data analysis accommodated the use of all available data without listwise deletion.

\section{Measures}

Demographics-Participants reported date of birth, years of education, race, and gender.

Perceived health-Perceived or self-rated health constitutes a single item assessing how participants perceive their health, ranging from 1 (Excellent) to 5 (Poor) (Hays \& Mazel, 1995). This measure is a robust prospective predictor of mortality above and beyond other risk factors and is linked to limited future time perspective (DeSalvo, et al., 2005; Kooij \& Van De Voorde, 2011). Perceived health was reverse-scored so higher scores indicated better perceived health and was assessed at both visits.

Beliefs about Savoring-The Savoring Beliefs Inventory (SBI; Bryant, 2003) consists of three subscales ( 8 items each) rated on a 7 -point scale $(1=$ strongly disagree; $7=$ strongly agree) measuring participants' perceived ability to savor positive experience through anticipation (Anticipation; e.g., "I feel a joy of anticipation when I think about upcoming good things"), present-moment enjoyment (Savoring; e.g., "I feel fully able to appreciate good things that happen to me), and reminiscence (Reminiscing; e.g., "I enjoy looking back 
on happy times from my past"). The SBI was administered at both visits. Composite reliability estimates were derived from a confirmatory factor analysis (CFA), and were adequate for all subscales (Anticipation $=.82$, Savoring $=.82$, and Reminiscing $=.84$ ) (Gaskin, 2012; Hair, Black, Babin, \& Anderson, 2010).

Positive Affect-The Geriatric Depression Scale (GDS; Yesavage et al., 1983) is designed to measure affect in older adults without including somatic symptoms associated with aging. There are 10 yes-no items that reflect positive affect (e.g., "Do you feel happy most of the time?"). Such items from depression scales are commonly used to derive measures of positive affect, and these measures predict health outcomes independently from the negative affect component of depression (e.g., Moscowitz, 2008). Positive affect was measured six times over the $2 \frac{1}{2}$ year period. Time points were aggregated to obtain average positive affect during the follow-up. This scale demonstrated adequate internal consistency for the present study $(a=65)$. The lower alpha level may be due to the dichotomous nature of responses and the use of only ten items.

\section{Data analysis}

We conducted a maximum-likelihood CFA in AMOS 21 to examine the factor structure of the SBI in this sample of older adults, as most prior work utilizing this scale has been conducted in younger samples. Bivariate analyses (correlations and paired-sample t-tests) assessed mean and rank-order stability in savoring facets and perceived health across time points. Finally, using structural equation models (SEM) in AMOS, cross-lagged panel analyses examined the relation between each facet of savoring (Anticipation, Reminiscing, and Savoring) and perceived health over the two visits. Due to missing data at follow-up, means and intercepts were estimated using maximum likelihood estimation. Non-significant paths were trimmed from the models, and standardized parameter estimates are reported for retained paths. Fit indices including the $\chi^{2} / \mathrm{df}$ statistic, CFI, and RMSEA were used to evaluate fit of the model to the data (with good fit defined as $\chi^{2} / \mathrm{df}<3$, CFI $>.95$, and RMSEA $\leq .07$; Hoe, 2008; Hooper, Coughlan, \& Mullen, 2008; Tabachnick \& Fidell, 2007). Though our sample size is relatively modest, it is in line with lower-boundary guidelines set forth by Bentler and Chou (1987) of 5-10 participants per tested parameter $\left(N_{\text {parameters }}=16\right.$ in the cross-lagged models, $N_{\text {participants }}$ parameter $=8.2$ ).

\section{Results}

Results of the CFA examining the factor structure of the SBI are reported in Table 1. As recommended by Bryant (2003), we tested a three-factor model (i.e., Anticipation, Reminiscing, and Savoring) and included Positive and Negative method factors (indicating whether the question phrasing was negative or positive). We pooled data from both time points due to our relatively small sample size. As pooling data violates the assumption of independence, standard errors may have been mis-estimated. However, path parameters were accurately estimated and can be compared with a previous study of the SBI with older adults (Bryant, 2003). Overall, the model fit the data well according to only 1 of the 3 fit indices $\left(\chi^{2} / \mathrm{df}=2.70, \mathrm{CFI}=.82, \mathrm{RMSEA}=.086\right)$; however, the factor loadings across the two time 
points were in line with expectations for the scale and similar to those reported by Bryant (2003), suggesting that the factors were appropriate for use in this sample of older adults.

SBI components and perceived health exhibited high rank-order stability (Table 2). There were significant declines in Reminiscing (Time $1 \mathrm{M}=47.40$ ( $\mathrm{SD}=6.52$ ), Time $2 \mathrm{M}=45.97$ $(\mathrm{SD}=6.28), t(100)=2.65 ; p=.009)$ and Anticipation (Time $1 \mathrm{M}=47.76(\mathrm{SD}=5.66)$, Time $2 \mathrm{M}=45.40(\mathrm{SD}=6.25), t(99)=3.92 ; p<.001$ ) between baseline and follow-up. Savoring did not increase over time as hypothesized, but remained stable rather than significantly declining as did the other facets (Time $1 \mathrm{M}=46.33$ ( $\mathrm{SD}=6.44$ ), Time $2 \mathrm{M}=45.97$ ( $\mathrm{SD}=$ 6.01).

Three cross-lagged structural models examined relations over time between Anticipation, Reminiscing, Savoring, and perceived health. Cross-lagged model results are shown in Figure 1 (for beta and standard error values, see Table 3). The model for Anticipation had adequate fit according to the $\chi^{2} / \mathrm{df}$ and CFI indices (but not RMSEA), $\chi^{2}(1)=2.53$, CFI $=$. 98 , RMSEA $=.11$. The retained cross-lagged path indicated that participants with better perceived health at baseline reported greater Anticipation at follow-up. ${ }^{1}$ Anticipation at baseline was not related to perceived health at follow-up. The model for Reminiscing had adequate fit according to the $\chi^{2} / \mathrm{df}$ and CFI indices (but not RMSEA), $\chi^{2}(1)=2.16, \mathrm{CFI}=$. 99 , RMSEA $=.094$. Findings were parallel to those for Anticipation, in that perceived health and Reminiscing were largely stable over time, and better perceived health at baseline predicted greater Reminiscing at follow-up. Reminiscing at baseline did not predict perceived health at follow-up. The model for Savoring fit the data well according to all 3 indices, $\chi^{2}(1)=.080, \mathrm{CFI}=1.0, \mathrm{RMSEA}=.00$. The cross-lagged associations demonstrated the opposite pattern from that of the other two savoring facets in that better perceived health at baseline did not predict Savoring at follow-up, but greater Savoring at baseline predicted better perceived health at follow-up.

Follow-up analyses included positive affect in the model, to determine if positive mood during the follow-up period mediated the relationship between baseline Savoring and perceived health at follow-up (see final panel of Figure 1). The model for Savoring including positive affect fit the data well according to all three indices, $\chi^{2}(1)=.115, p=.73$, CFI $=$ 1.0, RMSEA $=.00$. After including positive affect, the direct path from baseline Savoring to perceived health at follow-up was no longer statistically significant ( $\beta$ declined from .15 to . 10). Therefore, part of the effect of Savoring on change in perceived health ran through positive affect (for parameter estimates, see Table 3).

Supplemental analyses examined whether subscale effects were due to a general savoring beliefs latent factor; these analyses supported direct effects of the facets rather than indirect effects through general savoring beliefs (see Supplementary Online Material.)

\footnotetext{
${ }^{1}$ One participant had a substantially lower score (>3 SD from the mean) for follow-up Anticipation, though the remainder of the scores were not deviant. The anticipating model was conducted after using the expectation-maximization method to replace the value, and results were largely parallel, though the path linking baseline $\mathrm{PH}$ and follow-up Anticipation was marginally significant $(\beta=.14, p$ $=.08)$.
} 


\section{Discussion}

Savoring is a temporally specific emotion regulation strategy linked to higher emotional well-being. In the present study, perceived savoring ability remained stable across a $21 / 2$ year period and predicted better perceived health in a sample of older adults. In contrast, perceived reminiscing and anticipation abilities significantly declined across $2 \frac{1}{1} 2$ years, although older adults who reported better perceived health at baseline reported greater perceived reminiscing and anticipation abilities at follow-up. These results suggest future time perspective may differentially impact components of perceived savoring abilities in older adults.

\section{Changes in Savoring Over Time}

The decrease in perceived anticipation ability from baseline to follow-up was expected, given older adults' diminishing future time perspective and difficulty anticipating future events. Decreases in perceived reminiscing ability was unexpected, as older adults use reminiscing to effectively maintain well-being (Bohlmeijer et al., 2007). One possible explanation of this finding is the reminiscing subscale's emphasis on memory (e.g., like to store memories for later recall). Many older adults believe "normal" aging includes cognitive decline and memory problems (e.g., Levy, 2003). Consequently, older adults may change beliefs about their abilities to match currently held perceptions about aging. As a result, declines in perceived reminiscing ability may be driven by assumptions about aging rather than actual reminiscing ability.

Cognitive function also might contribute to a link between reminiscence and rumination. While these two constructs may not appear to be related, they both operate using the same mental process: thinking about past events. Although reminiscence has led to positive outcomes, reviewing past events can also lead to dysfunction (Butler, 1963). Rumination entails negatively valenced repetitive thought about oneself and one's world (e.g., NolenHoeksema, 1991). The declining executive function of older adults increases their risk of ruminative thinking (e.g., Segerstrom et al., 2010). Higher rumination predicts higher depression in older adults, particularly among older adults who engage in reminiscence (Brinker, 2013). Because both reminiscence and rumination involve thinking about past events, older adults may feel less able to reminisce without detouring into rumination. To test this possibility, we examined the correlations between rumination (rumination subscale of the Rumination Reflection Questionnaire; Trapnell \& Campbell, 1999), Reminiscing, and Savoring at baseline in the current sample. Savoring correlated more strongly and negatively with rumination $(r=-.44, p<.001)$ than did Reminiscing $(r=-.22, p=.01)$, offering preliminary support that overlap with rumination is less likely to influence perceived savoring ability than reminiscing ability.

\section{Perceived Health as a Predictor of Savoring}

Poorer perceived health is linked to limited future time perspective (Kooij \& Van De Voorde, 2011). In this sample, poorer perceived health at baseline predicted less perceived reminiscing and anticipation abilities, but not perceived savoring ability, at follow-up. This offers evidence that decreased future time perspective reduces older adults' perceived 
anticipation and reminiscing abilities, but does not affect perceived savoring ability. This pattern of findings is consistent with predictions from SST theory, positing that limited future time emphasizes present moment awareness (Carstensen et al., 1999). The current findings support the importance of perceived savoring ability for well-being in older adulthood.

\section{Savoring as a Predictor of Perceived Health}

Higher levels of perceived savoring, but not anticipation or reminiscing abilities at baseline predicted better perceived health at follow-up. These findings are supported by the extant link between present-moment attention and positive health outcomes. In younger adults, dispositional mindfulness (present-moment awareness) and positive affectivity improve physical health (e.g., Grossman et al., 2004; Ong et al., 2011). Likewise, these analyses suggest part of the relationship between perceived savoring ability and future perceived health is due to positive affect.

Because perceived savoring ability is linked to positive perceived physical and mental health outcomes, its clinical significance should be explored. An intervention to increase savoring the present moment in younger adults reduced self-reported depression and negative affect (Hurley \& Kwon, 2012). Mindfulness-based interventions emphasizing present-moment awareness reduce depression and anxiety and improve health outcomes related to medical illness (Grossman et al., 2004). Although mindfulness's focus is on all present moment events, mindfulness-based interventions emphasize the importance of present-moment focus on positive experiences, providing additional support for savoring's clinical significance.

\section{Limitations and Future Directions}

The present study used a self-report measure to assess beliefs about savoring. Future research should utilize inductions to investigate all facets of savoring engagement. Future studies should also use a more discriminating measure of positive affect. In addition, selfreported future time perspective was not measured. However, older age and perceived illbeing are two objective cues that people are getting nearer to the end of life that have been empirically linked to limited future time (e.g., Kooij \& Van De Voorde, 2011). Future studies should also control and examine additional variables related to savoring beliefs. For example, examining the effects of beliefs about aging (e.g., Expectations Regarding Aging Survey (ERA-12) or cognitive impairment on savoring ability may help explain changes over time. The present sample was a homogenous, healthy, and well-educated group. Future research should use more diverse samples. Assessing perceived savoring abilities and perceived health at two time points is an improvement over cross-sectional designs; additional time points may have been valuable to further assess stability of savoring beliefs and associated cross-lagged effects. Future studies may also benefit from collecting larger samples in order to be appropriately powered to test more complex models. Despite these limitations, the current study is the first to examine longitudinal changes in perceived savoring abilities ability in older adults, and how perceptions of physical health differentially impact these changes. 
Clinical interventions targeting anticipation and reminiscing abilities may be particularly helpful for older adults. Should declines in perceived reminiscing ability be related to inaccurate perceptions of aging, education on aging may dispel stereotypes leading to greater confidence in reminiscence. Increasing confidence in reminiscence and anticipation afford the older adult with additional tools to promote psychological wellbeing.

\section{Supplementary Material}

Refer to Web version on PubMed Central for supplementary material.

\section{Acknowledgments}

This research was supported by the Dana Foundation and the National Institute of Aging (AG026307-R01, AG033629-K02, AG028383-P30, AG048697-F31).

\section{References}

Bal M, Jansen PGW, Velde EG, de Lange AH, Rousseau DM. The role of future time perspective in psychological contracts. A study among older workers. Journal of Vocational Behavior. 2010; 76:474-486.

Bentler PM, Chou CP. Practical issues in structural modeling. Sociological Methods Research. 1987; 16:78-117.

Bohlmeijer E, Roemer M, Cuijpers P, Smit F. The effects of reminiscence on psychological well-being in older adults: A meta-analysis. Aging \& Mental Health. 2007; 11:291-300. [PubMed: 17558580]

Brinker JK. Rumination and reminiscence in older adults: implications for clinical practice. European Journal of Ageing. 2013; 10:223-227.

Bryant FB. A four-factor model of perceived control: Avoiding, coping, obtaining, and savoring. Journal of Personality. 1989; 57:773-797.

Bryant FB. Savoring beliefs inventory (SBI): A scale for measuring beliefs about savouring. Journal of Mental Health. 2003; 12(2):175-196.

Butler RN. The life review: an interpretation of reminiscence in aged. Psychiatry. 1963; 26:65-78. [PubMed: 14017386]

Carstensen LL, Isaacowitz DM, Charles ST. Taking time seriously: A theory of socioemotional selectivity theory. American Psychologist. 1999; 54:165-181. [PubMed: 10199217]

Carstensen LL, Fung H, Charles ST. Socioemotional selectivity theory and emotion regulation in the second half of life. Motivation and Emotion. 2003; 27:103-123.

Charles ST, Carstensen LL. Social and emotional aspects of aging. Annual Review of Psychology. 2010; 61:383-409.

DeSalvo KB, Bloser N, Reynolds K, He J, Muntner P. Mortality prediction with a single general selfrated health question: A meta-analysis. Journal of General Internal Medicine. 2005; 20:267-275. [PubMed: 15836531]

Gaskin, J. ValidityMaster: Stats Tool Package. 2012. Retrieved from http://statwiki.kolobkreations.com

Grossman P, Niemann L, Schmidt S, Walach Harald. Mindfulness-based stress reduction and health benefits: A meta-analysis. Journal of Psychosomatic Research. 2004; 57(1):35-43. [PubMed: 15256293]

Hair, J., Black, W., Babin, B., Anderson, R. Multivariate data analysis. 7. Prentice-Hall, Inc; Upper Saddle River, NJ, USA: 2010.

Hays, RD., Sherbourne, CD., Mazel, RM. RAND: User's manual for the medical outcomes study (MOS) core measures of health-related quality of life. Santa Monica, CA: RAND; 1995.

Hoe SL. Issues and procedures in adopting structural equation modeling technique. Journal of Applied Quantitative Methods. 2008; 3(1):76-83. 
Hooper D, Coughlan J, Mullen MR. Structural equation modelling: Guidelines for determining model fit. The Electronic Journal of Business Research Methods. 2008; 6(1):53-60.

Hurley DB, Kwon P. Results of a study to increase savoring the moment: Differential impact on positive and negative outcomes. Journal of Happiness Studies. 2012; 13(4):579-588.

Hurley DB, Kwon P. Savoring helps most when you have little: Interaction between savoring the moment and uplifts on positive affect and life satisfaction. Journal of Happiness Studies. 2013; 14:1261-1271.

Kooij D, Van De Voorde K. How changes in subjective general health predict future time perspective and development and generativity motives over the lifespan. Journal of Occupational and Organizational Psychology. 2011; 84:228-247.

Kurtz J. Looking to the future to appreciate the present. Psychological Science. 2008; 19:1238-1241. [PubMed: 19121130]

Larsen RJ. Toward a science of mood regulation. Psychological Inquiry. 2000; 11:129-141.

Mammarella N, Di Domenico A, Palumbo R, Fairfield B. Noradrenergic modulation of emotional memory in aging. Ageing Research Reviews. 2016; 27:61-66. [PubMed: 27003374]

Moskowitz JT, Epel ES, Acree M. Positive affect uniquely predicts lower risk of mortality in people with diabetes. Health Psychology. 2008; 27(1S):S73-S82. [PubMed: 18248108]

Nolen-Hoeksema S. Responses to depression and their effects on the duration of depressive episodes. Journal of Abnormal Psychology. 1991; 100:569-582. [PubMed: 1757671]

Ong AD, Mroczek DK, Riffin C. The health significance of positive emotions in adulthood and later life. Social and Personality Psychology Compass. 2011; 5:538-551. [PubMed: 21927620]

Quoidbach J, Berry EV, Hansenne M, Mikolajczak M. Positive emotion regulation and well-being: Comparing the impact of eight savoring and dampening strategies. Personality and Individual Differences. 2010; 49:368-373.

Pressman, SD., Bowlin, SL. Positive affect: A pathway to better physical health. In: Gruber, J., Moskowitz, JT., editors. Positive emotion: Integrating the light sides and dark sides. New York, NY, US: Oxford University Press; 2014. p. 183-205.

Ramsey MA, Gentzler AL. Age differences in subjective well-being across adulthood: The roles of savoring and future time perspective. The International Journal of Aging \& Human Development. 2014; 78:3-22. [PubMed: 24669507]

Rendell PG, Bailey PE, Henry JD, Phillips LH, Gaskin S, Kliegel M. Older adults have greater difficult imaging future rather than atemporal experiences. Psychology and Aging. 2012; 27:1089-1098. [PubMed: 23002921]

Segerstrom SC, Roach AR, Evans DR, Schipper LJ, Darville AK. The structure and health correlates of trait repetitive thought in older adults. Psychology and Aging. 2010; 25:505-515. [PubMed: 20677888]

Spreng RN, Levine B. The temporal distribution of past and future autobiographical events across the lifespan. Memory \& Cognition. 2006; 34:1644-1651. [PubMed: 17489291]

Tabachnick, BG., Fidell, LS. Using multivariate statistics. 5. Boston, MA: Allyn \& Bacon/Pearson Education; 2007. 


\section{Highlights}

- Changes in savoring abilities over time are examined in a sample of older adults.

- $\quad$ Perceived anticipation and reminiscing abilities decline over time.

- $\quad$ Perceived savoring ability predicts better perceived health at follow-up.

- $\quad$ Aging and health status focus older adults' thoughts on present-moment pleasures. 


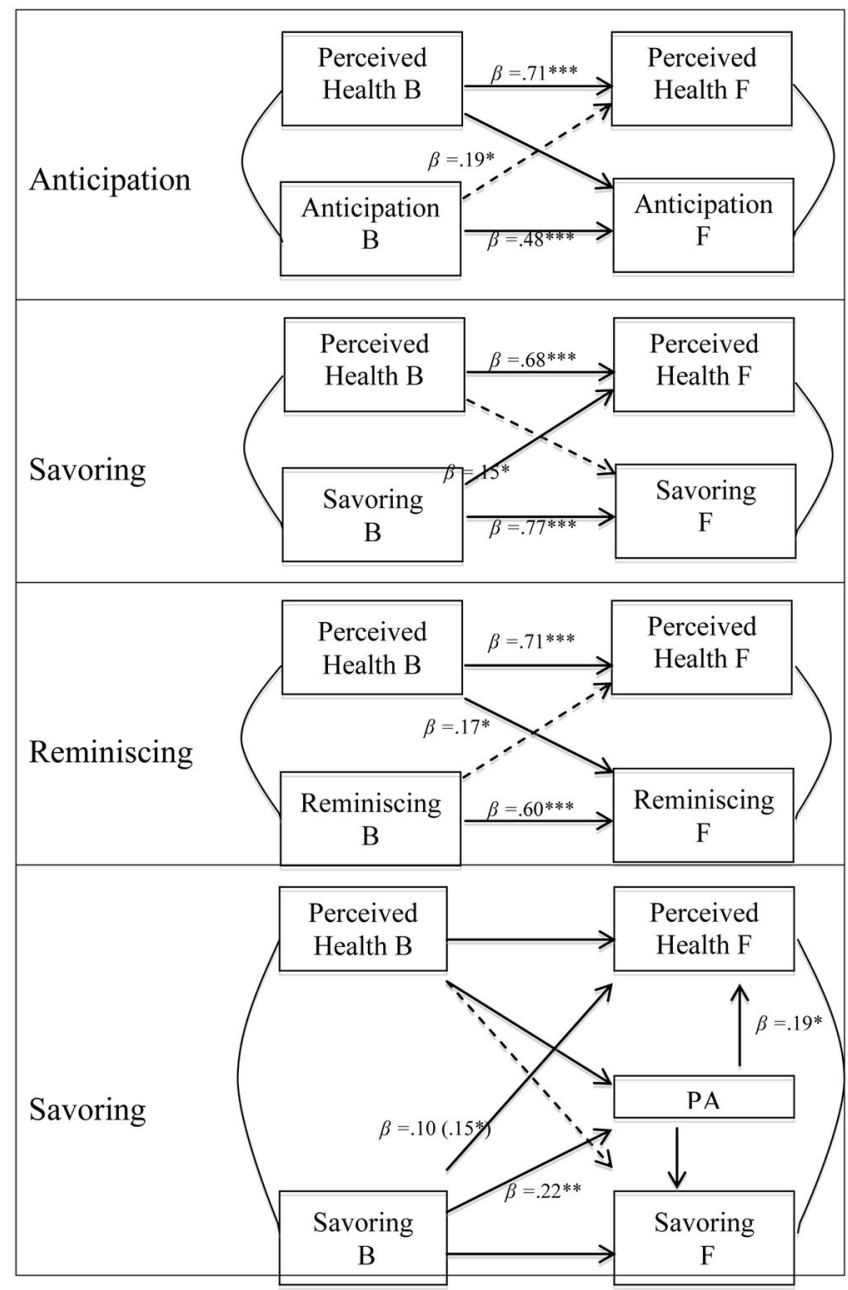

Figure 1.

Results of cross-lagged path models.

Note: $\mathrm{B}=$ baseline, $\mathrm{F}=$ follow-up. $\mathrm{PA}=$ positive affect. Trimmed paths are demarcated by dashed lines. $* \mathrm{p}<.05, * * \mathrm{p}<.01, * * * \mathrm{p}<.001$. 


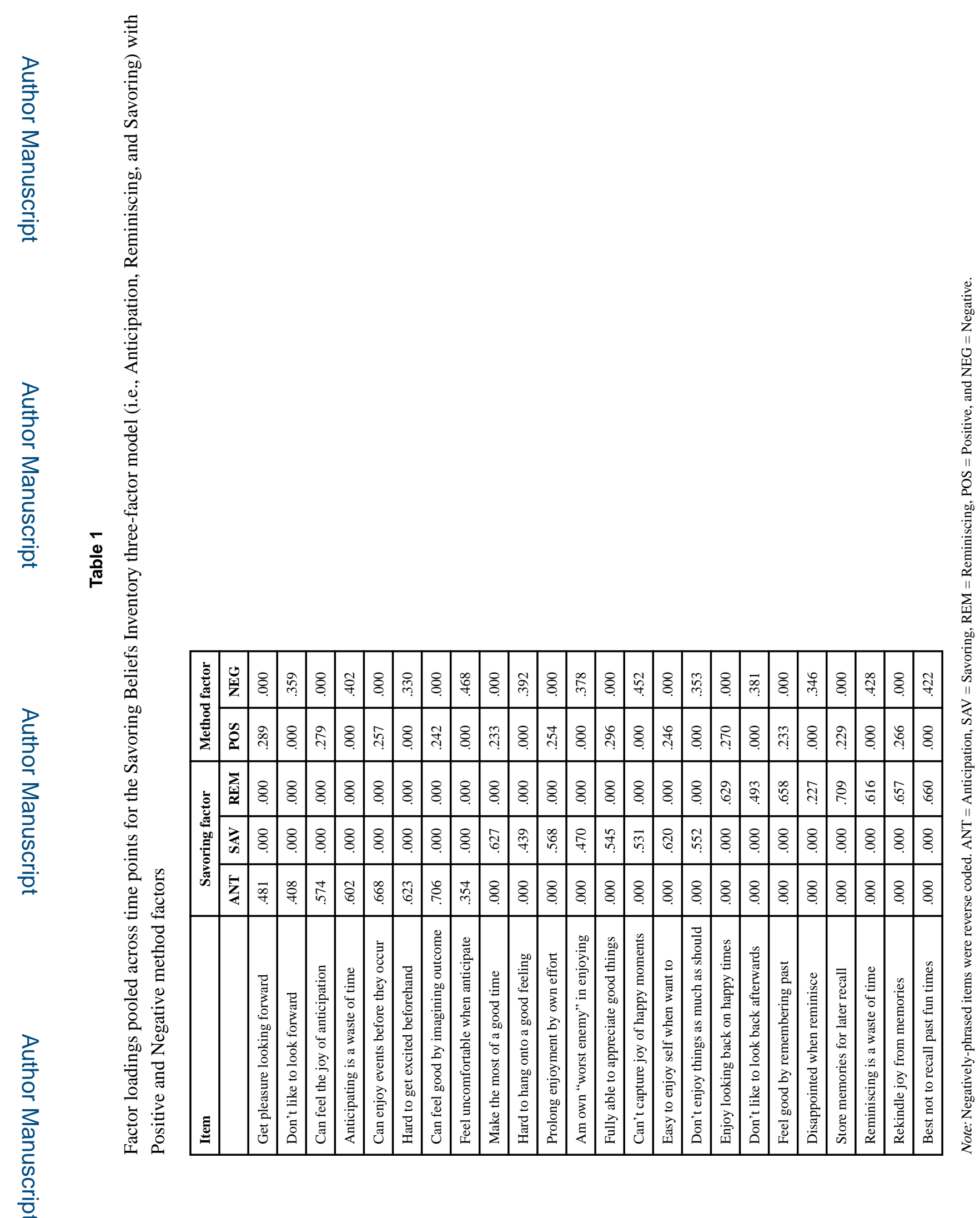

Pers Individ Dif. Author manuscript; available in PMC 2018 January 15. 


\section{로을}

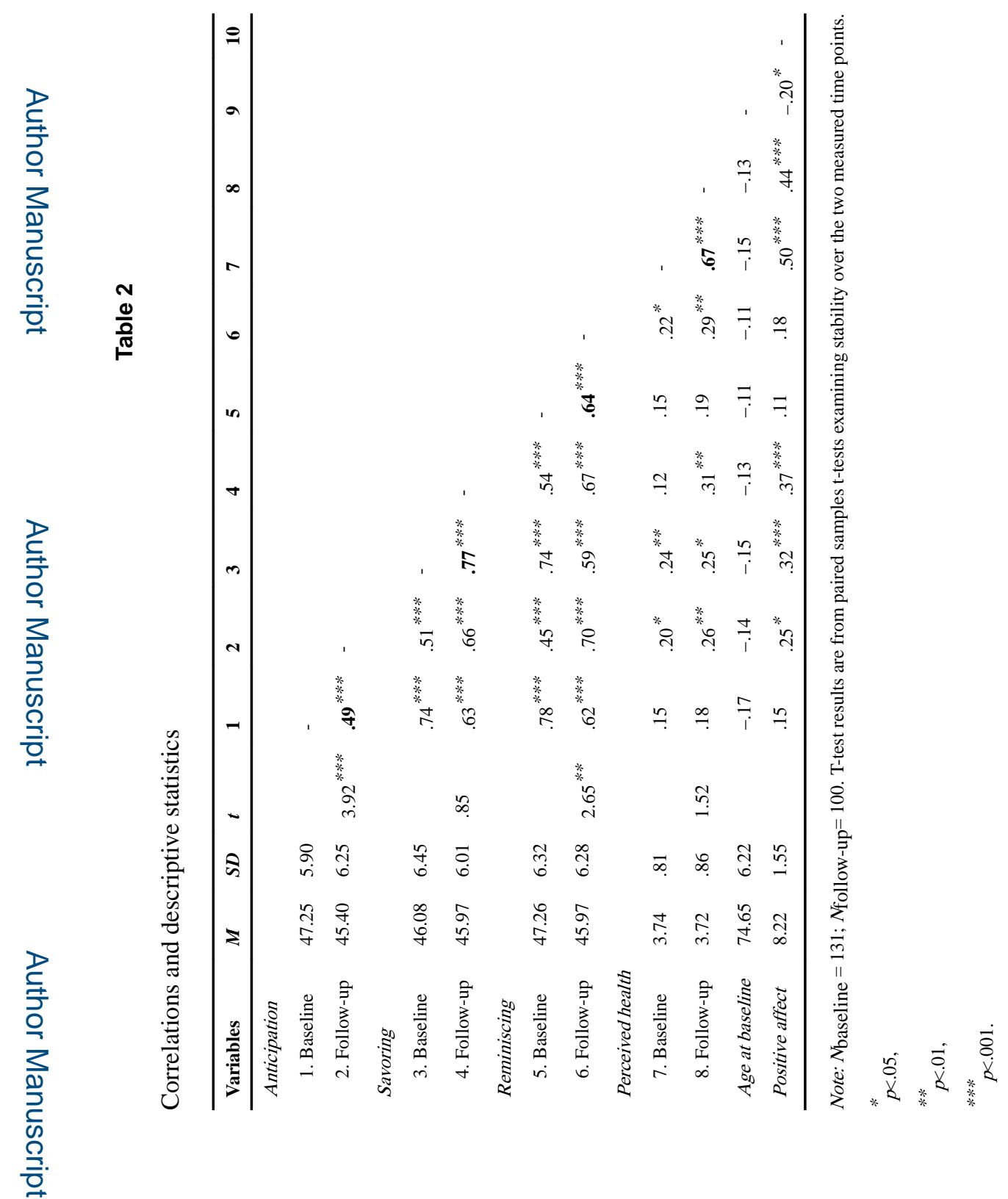

Pers Individ Dif. Author manuscript; available in PMC 2018 January 15. 


\section{Table 3}

Unstandardized B, Standard Error, and Significance Levels for Trimmed Models Reported in Figure $1(N=$ 131)

\begin{tabular}{|c|c|c|c|}
\hline Parameter Estimate & B & SE & $\mathbf{p}$ \\
\hline \multicolumn{4}{|l|}{ Anticipation } \\
\hline $\mathrm{PH}-\mathrm{B} \rightarrow \mathrm{PH}-\mathrm{F}$ & .81 & .08 & $<.001$ \\
\hline Anticipation $\mathrm{B} \rightarrow$ Anticipation $\mathrm{F}$ & .51 & .09 & $<.001$ \\
\hline PH- B $\rightarrow$ Anticipating F & 1.45 & .67 & .031 \\
\hline Covariance at B & .73 & .42 & .083 \\
\hline Covariance at $\mathrm{F}$ & .40 & .34 & .24 \\
\hline \multicolumn{4}{|l|}{ Savoring } \\
\hline $\mathrm{PH}-\mathrm{B} \rightarrow \mathrm{PH}-\mathrm{F}$ & .78 & .08 & $<.001$ \\
\hline Savoring $\mathrm{B} \rightarrow$ Savoring F & .72 & .06 & $<.001$ \\
\hline Savoring B $\rightarrow$ Perceived Health F & .02 & .01 & .032 \\
\hline Covariance at B & 1.24 & .47 & .008 \\
\hline Covariance at $\mathrm{F}$ & .57 & .24 & .02 \\
\hline \multicolumn{4}{|l|}{ Reminiscing } \\
\hline $\mathrm{PH}-\mathrm{B} \rightarrow \mathrm{PH}-\mathrm{F}$ & .81 & .08 & $<.001$ \\
\hline Reminiscing $\quad \mathrm{B} \rightarrow$ Reminiscing $\mathrm{F}$ & .59 & .08 & $<.001$ \\
\hline $\mathrm{PH}-\mathrm{B} \rightarrow$ Reminiscing $\mathrm{F}$ & 1.30 & .59 & .027 \\
\hline Covariance at B & .74 & .45 & .10 \\
\hline Covariance at $\mathrm{F}$ & .41 & .30 & .18 \\
\hline \multicolumn{4}{|l|}{ Savoring with $P A$} \\
\hline $\mathrm{PH}-\mathrm{B} \rightarrow \mathrm{PH}-\mathrm{F}$ & .72 & .09 & $<.001$ \\
\hline Savoring $\mathrm{B} \rightarrow$ Savoring $\mathrm{F}$ & .69 & .06 & $<.001$ \\
\hline Savoring $\mathrm{B} \rightarrow \mathrm{PH}-\mathrm{F}$ & .02 & .01 & .14 \\
\hline $\mathrm{PH}-\mathrm{B} \rightarrow \mathrm{PA}$ & .85 & .15 & $<.001$ \\
\hline Savoring $\mathrm{B} \rightarrow \mathrm{PA}$ & .05 & .02 & .004 \\
\hline $\mathrm{PA} \rightarrow \mathrm{PH}-\mathrm{F}$ & .12 & .05 & .015 \\
\hline $\mathrm{PA} \rightarrow$ Savoring $\mathrm{F}$ & .53 & .26 & .04 \\
\hline Covariance at B & 1.24 & .47 & .008 \\
\hline Covariance at $\mathrm{F}$ & .50 & .24 & .034 \\
\hline
\end{tabular}

Note. $\mathrm{PH}=$ Perceived Health; $\mathrm{B}=$ Baseline; $\mathrm{F}$ = Follow-up. 